\title{
Quantifying the Effects of Temperature and Relative Humidity on the Development of Wheat Blast Incited by the Lolium Pathotype of Magnaporthe oryzae
}

\author{
Karasi B. Mills, Laurence V. Madden, and Pierce A. Paul ${ }^{\dagger}$ \\ Department of Plant Pathology, The Ohio State University, Ohio Agricultural Research and Development Center, Wooster, OH \\ 44691
}

\begin{abstract}
The Triticum pathotype of Magnaporthe oryzae (MoT) that causes wheat blast has not yet been reported in the U.S., but the closely related M. oryzae Lolium pathotype (MoL), also capable of inciting blast, is found in several wheat growing regions. Since the epidemiology of MoLincited wheat blast is unknown, it is difficult to project where and under what conditions this pathogen may be of importance. To quantify conditions favorable for MoL infection and temporal development of wheat blast, separate cohorts of wheat spikes were spray or point inoculated at anthesis and immediately subjected to different combinations of temperature (TEMP; 20,25 , and $30^{\circ} \mathrm{C}$ ) and $100 \%$ relative humidity $(\mathrm{RH}) \mathrm{du}-$ ration $(0,3,6,12,24$, and $48 \mathrm{~h})$. Blast developed under all tested conditions, with both incidence (INC) and severity (SEV) increasing over time. The effects of TEMP on angular-transformed INC and SEV (arcINC and arcSEV) were significant $(P<0.05)$ in most cases, with the magnitude of the TEMP effect influenced by RH duration when
\end{abstract}

Abstract

spikes were spray-inoculated. Between 12 and 21 days after inoculation (DAI), there were significant, positive linear relationships between hours of high RH and arcINC and arcSEV at 25 and $30^{\circ} \mathrm{C}$, but not at $20^{\circ} \mathrm{C}$. The estimated rates of increase in transformed INC or SEV per hour increase in high $\mathrm{RH}$ duration were significantly higher at $30^{\circ} \mathrm{C}$ than at $25^{\circ} \mathrm{C}$ at 12 to $14 \mathrm{DAI}$, but not at 19 to $21 \mathrm{DAI}$. The highest estimated temporal rates of increase in INC and SEV and the shortest estimated incubation periods (5 to 8 days) occurred at 25 and $30^{\circ} \mathrm{C}$, with 24 and $48 \mathrm{~h}$ of high $\mathrm{RH}$ immediately after inoculation. These results will contribute to ongoing efforts to better understand the epidemiology of wheat blast incited by MoL as well as MoT.

Keywords: fungi, epidemiology, disease development and spread, climate/weather effects, field crops, cereals and grains, wheat blast, Lolium pathotype

Magnaporthe oryzae is an ascomycetous fungal pathogen that causes diseases on more than 50 graminaceous plant species worldwide, including economically important crops such as wheat, rice, millet, barely, and ryegrass (Tosa et al. 2004). The taxonomy of this pathogen has been the subject of debate for years (Castroagudın et al. 2016; Ceresini et al. 2018, 2019; Cruz and Valent 2017; Gladieux et al. 2018; Valent et al. 2019), but one very commonly used and generally accepted classification is pathotype (Cruz and Valent 2017). A pathotype is a subspecific designation that is based on host specialization or adaptation (Ceresini et al. 2018; Cruz and Valent 2017; Valent et al. 2019). We follow this naming convention here. One of the most concerning diseases caused by the Triticum pathotype of $M$. oryzae (MoT) is wheat blast. This disease is characterized by partial or complete bleaching and discoloration of spikes with shriveled, lightweight kernels (Goulart et al. 2007), and in some cases, leaves with oblong lesions with dark edges and light gray centers (Saharan et al. 2017). Wheat blast is endemic in several wheat growing regions of South America (Kohli et al. 2011) and recently emerged as a threat to wheat production in South Asia (Cruz and Valent 2017; Sadat and Choi 2017; Saharan et al. 2017). While MoT has not yet been reported in the U.S., there are several native pathotypes of $M$. oryzae that cause diseases on other crops. For instance, the Lolium pathotype $(\mathrm{MoL})$ is the causal agent of gray leaf spot (GLS), a major disease

${ }^{\dagger}$ Corresponding author: P. A. Paul; paul.661@osu.edu

Funding: This project was supported by Agriculture and Food Research Initiative Competitive Grant no. 2013-68004-20378 from the United States Department National Institute of Food and Agriculture and The Ohio State University Department of Plant Pathology. Salaries and research support for K. B. Mills, L. V. Madden, and P. A. Paul were provided by state and federal funds to the Ohio Agricultural Research and Development Center.

The author(s) declare no conflict of interest.

Accepted for publication 13 April 2020.

(C) 2020 The American Phytopathological Society of turfgrasses such as tall fescue (Festuca arundinacea) and perennial ryegrass (Lolium perenne) (Farman et al. 2017; Harmon and Latin 2003; Milazzo et al. 2019), and the Oryzae pathotype (MoO) is the causal agent of rice blast, another economically important disease of global significance (Greer and Webster 2001).

Several studies have been conducted in an effort to determine the host range and phylogenetic relatedness of $M$. oryzae populations from different host species (Ceresini et al. 2018, 2019; Couch et al. 2005; Urashima et al. 1993). Some subgroups or isolates have fairly wide, overlapping host ranges, including crops and weeds that sometimes grow in close proximity to one another, while other subgroups are more host specific (Ceresini et al. 2018, 2019; Urashima et al. 1993). For instance, based on greenhouse experiments with seedlings, Urashima et al. (1993) reported that several isolates of the blast pathogen from rice (referred to as Pyricularia grisea) caused foliar symptoms on wheat, whereas isolates from wheat did not produce symptoms on any of the rice cultivars tested, but induced typical, sporulating lesions on leaves of perennial ryegrass, tall fescue, and finger millet (Eleusine coracana). This led them to hypothesize, following compatibility crosses, that wheat isolates were different from rice isolates, but similar to those from finger millet. This hypothesis was supported by results from recent phylogenetic studies showing that wheat-infecting isolates were more closely related to turfgrassinfecting isolates than to rice-infecting isolates (Castroagudın et al. 2016; Ceresini et al. 2018, 2019; Farman et al. 2017; Gladieux et al. 2018). Some researchers believe that MoT evolved from MoL in Brazil "through functional losses of a host specificity determinant" (Inoue et al. 2017). They theorized that MoL isolates carrying the PWT3 and PWT4 avirulence genes (which made them avirulent on wheat cultivars carrying the $R w t 3$ and $R w t 4$ resistance genes) infected highly susceptible $r w t 3$ cultivars that were widely grown during the first wheat blast outbreaks (Inoue et al. 2017). Once MoL became established on susceptible wheat, specialization occurred following mutation and the loss of function of $P W T 3$, eventually leading to the evolution of the MoT pathotype.

In 2011, a single wheat spike was found in Kentucky exhibiting typical signs and symptoms of wheat blast. Subsequent genetic analysis of the fungus isolated from that spike suggested that MoL was 
the likely causal agent. This was based on the fact that the genome sequence of that isolate was more similar to native U.S. MoL than to South American MoT pathotypes of M. oryzae (Farman et al. 2017). This was the first, and to date the only, observed case of naturally occurring wheat blast under field conditions in the U.S. However, the fact that several local isolates of MoL collected years before the Kentucky find were capable of causing blast on U.S. wheats under controlled conditions led some researchers to speculate that previous occurrences of blast may have been misdiagnosed as Fusarium head blight, a disease of similar symptomatology (Farman et al. 2017). Other growth chamber and field studies showed that most U.S. hard red winter wheats, particularly cultivars without the 2NS translocation from Aegilops ventricosa, were susceptible to South American MoT (Cruz et al. 2012, 2016), and that several U.S. soft red winter wheats were susceptible to both MoT and MoL (Mills et al. 2015). These results indicate that the U.S. wheat crop is at risk for infection both from an incursion of MoT as well as from native MoL isolates. The latter is of concern particularly in areas where wheat production overlaps with the occurrence of GLS on perennial ryegrass. However, the fact that winter wheat is harvested between late spring and early summer, well before GLS typically develops (Uddin et al. 2003b) and MoL inoculum builds up, may in part explain why natural MoL infections are not more frequent (Farman et al. 2017).

The possibility of MoL-incited wheat blast becoming more frequent in the U.S. served as the impetus for this research, which was part of a larger project to investigate the risk posed by MoL to U.S. wheat. The primary goal was to identify host, pathogen, and environmental risk factors associated with MoL infection and wheat blast development. The specific objectives of our research were to i) quantify the effects of temperature and initial high relative humidity $(\mathrm{RH})$ duration on MoL infection and spread within winter wheat spikes, and ii) model the temporal change in wheat blast intensity as influenced by temperature and $\mathrm{RH}$ duration. To accomplish these objectives, two methods of inoculation (Andersen et al. 2015) were employed, inoculated spikes were exposed to different temperature and $\mathrm{RH}$ regimes, and growth models were fitted to the resulting spike blast incidence and severity data. Mean blast incidence and severity, progress curves, and estimated regression parameters were used to compare blast dynamics among the tested temperature-RH regimes. Findings from this study will be of value for developing models to project where and when blast could develop in the U.S. as a result of infection by native MoL.

\section{Materials and Methods}

Preparation and maintenance of plants. Three experiments were conducted between 2015 and 2017 in walk-in growth chambers (Conviron BDW40, Winnipeg, MB, Canada) in The Ohio State University Plant Pathology phytotron facility, Wooster, OH. Fungicidetreated seeds of the highly MoL-susceptible hard red winter wheat cultivar Everest and an MoL- and MoT-susceptible soft red winter wheat cultivar (Mills et al. 2015) were sown in plastic trays. Once seeds germinated, they were vernalized in a cold room at $3{ }^{\circ} \mathrm{C}$, with fluorescent grow lights set to run $16 \mathrm{~h}$ on and $8 \mathrm{~h}$ off for approximately 10 weeks. After vernalization, trays were placed in Conviron growth chambers for a week, with a temperature progression program that ramped up from 6 to $16^{\circ} \mathrm{C}$ during each 24-h period, mimicking the natural spring temperature cycle of Wooster, $\mathrm{OH}$. Chambers were programmed with a fixed photoperiod of $16 \mathrm{~h}$ of light and $8 \mathrm{~h}$ of darkness, and relative humidity was maintained between 75 and $95 \%$ (mean of approximately $80 \%$ ).

After the first week in the growth chambers, individual tillers were transplanted to cone-tainers (Stuewe and Sons, Inc. Corvallis, OR) filled with autoclaved, unamended silt loam soil. In each experiment, there were three growth chambers, each containing three carts on which four cone-tainer trays with 98 cones were placed. Minimum and maximum daily temperatures were programmed to increase by $2^{\circ} \mathrm{C}$ per week from week 2 to week 5 (week 2: 8 and $18^{\circ}$; week 3: 10 and $20^{\circ}$; week 4: 12 and $22^{\circ}$; week 5: 14 and $24^{\circ}$ ). Once the growth chambers reached the week 5 temperature regime, the temperature cycle was maintained until plants reached the Feekes 10.5 (full head emergence) growth stage, after which the specific temperature treatments were assigned. The daily and weekly temperature cycles helped to promote uniform and synchronized plant development. Built-in sensors monitored and logged temperature, relative humidity, and light settings.

Plants were checked daily, watered as needed, and fertilized once a week with a nutrient solution. Powdery mildew was controlled as needed with 50\% triadimefon (Baleton 50; Bayer CropScience, Research Triangle Park, NC), and $21.4 \%$ imidacloprid (Marathon II; OHP Inc., Mainland, PA) was used to control aphids and fungus gnats.

Experimental design, inoculum preparation, and inoculation. The experimental design was a randomized complete block (with three experimental repeats as the blocking factor), with a splitsplit-plot arrangement of temperature as whole-plot, cultivar as subplot, and RH duration as sub-sub-plot. Once plants reached the Feekes 10.5 growth stage, approximately 7 weeks after vernalization, each growth chamber was set to a fixed temperature of 20,25 , or $30^{\circ} \mathrm{C}$. The $16-\mathrm{h}$ photoperiod and $\mathrm{RH}$ of approximately $80 \%$ were maintained in all chambers. As spikes reached Feekes 10.5.1 (early anthesis), they were arbitrarily assigned to one of the temperature treatments/growth chambers, point- or spray-inoculated as described by Andersen et al. (2015), and subjected to $0,3,6,12,24$, or $48 \mathrm{~h}$ of high RH (>95\%) immediately after inoculation. The intent of the two methods of inoculation was to address specific questions about infection, spread within the spike (colonization), and blast development as influenced by the imposed temperature and RH treatments.

MoL isolate PL2-1 (Farman et al. 2017; Valent et al. 2019), previously collected from Lolium multiflorum in Kentucky, was used for inoculation. PL2-1 was reported to be $75 \%$ as aggressive as an isolate of MoT from Bolivia (Farman et al. 2017). Prior to conducting the experiment, PL2-1 was used to infect spikes of susceptible cultivar Everest for a cursory assessment of its ability to cause blast and to increase inoculum from diseased tissue. Single-spore colonies were grown in Petri plates with autoclaved filter paper (about $1 \mathrm{~mm} \times$ $1 \mathrm{~mm}$ ) placed on oatmeal agar (30 g/liter quick cook oatmeal; 15 $\mathrm{g} /$ liter granulated agar; $10 \mu \mathrm{g} / \mathrm{liter}$ Carbenicillin). Plates were incubated at room temperature under near-ultraviolet light for a 16-h light, 8-h dark photoperiod. Once sporulation was observed (7 to 14 days after incubation), the filter paper pieces were collected and stored in tubes at $-20^{\circ} \mathrm{C}$ until needed. To produce inoculum for the experiment, a single piece of filter paper was placed in the center of a Petri dish of oatmeal agar and incubated for about 10 days, after which conidia were harvested with a rubber policeman and sterilized water. Spore concentration was estimated using a hemocytometer and diluted using sterilized water to 20,000 spores $/ \mathrm{ml}$ for spray inoculum and 1,000 spores $/ \mathrm{ml}$ for point inoculum. A drop of Tween 20 was added to every $50 \mathrm{ml}$ of final spore suspension.

Spray-inoculated spikes were inoculated using a spray bottle, with approximately $2 \mathrm{ml}$ of the spore suspension covering the surface of the spike. For spikes that were point-inoculated, the glume, lemma, and palea of the central floret of a spikelet in the middle of the spike were gently peeled back and a drop $(10 \mu \mathrm{l})$ of the spore suspension was deposited directly into the floret (Andersen et al. 2015). The two types of inoculations were performed separately to minimize cross contamination. Inoculated spikes were then covered with a clear $0.3 \mathrm{~mm}$ plastic bag and secured closed with a tie for $3,6,12,24$, or $48 \mathrm{~h}$, depending on the $\mathrm{RH}$ treatment. During this period, respiration and water from the spore suspension kept the surface of sprayinoculated spikes wet, and consequently at high $(>95 \%) \mathrm{RH}$, until the bags were removed. To ensure similar wetness and maintain high $\mathrm{RH}$ in point-inoculated spikes, approximately $0.5 \mathrm{ml}$ of lab grade water was sprayed inside the plastic bags immediately before they were placed over the spikes. Check spikes (the 0-h high RH treatment) were left uncovered and exposed to the ambient RH ( 80\%) inside the growth chamber. A piece of flagging tape with a unique identifier (for each spike $\times$ treatment-RH $\times$ inoculation method combination) was attached to the peduncle of each spike at the time of inoculation so that disease progression of individual spikes could be monitored. 
Data collection, organization, and analysis. Disease assessment. The first set of spike blast assessments was made between 3 and 7 days after inoculation (DAI) and repeated every 3 to 7 days until approximately Feekes growth stage 11 (milky ripe), when senescence made it difficult to distinguish diseased spikelet from natural bleaching. Percent blast severity was estimated on each spike by counting the number of bleached spikelets, dividing by the total number of spikelets, and multiplying by 100 . This is equivalent to incidence at the spikelet scale (Paul et al. 2005). Blast incidence at the level of each experimental unit was estimated from individualspike severity as the number of diseased spikes, divided by the total number of spikes rated, multiplied by 100 . The number of spikes rated per experimental unit varied among treatment combinations and among assessment times for a given combination. This was partly due to the effect of temperature on crop growth and development, which resulted in some experimental units having a very small number of spikes at the time of the first and last sets of assessments. For instance, cool conditions in experimental units subjected to the $20^{\circ} \mathrm{C}$ treatment delayed anthesis and crop maturity, and consequently extended the duration of the blast epidemics. On the other hand, plants exposed to the $30^{\circ} \mathrm{C}$ treatment matured early and more uniformly, leading to epidemics of shorter duration. To minimize these effects and facilitate comparisons of means among treatments, spikes were pooled over three-day windows at 5 to 7 days, 12 to 14 days, 19 to 21 days, and 26 to 28 DAI. Each window was treated as a separate response variable for analysis (i.e., analysis done separately for each time period). Instead of attempting repeated measures analyses of the data, the effect of time on blast development as influenced by temperature and RH was quantified through the fit of growth models (see below). Most spikes subjected to the $30^{\circ} \mathrm{C}$ treatment senesced before 26 to $28 \mathrm{DAI}$, so less emphasis is given to this final time period.

Linear mixed model analysis (LMM). The GLIMMIX procedure of SAS (Stroup et al. 2018) was used to fit separate linear mixed models to data from the point- and spray-inoculated experiments to determine the effects of temperature, cultivar, and RH duration on spike blast INC and SEV at 5 to 7,12 to 14,19 to 21 , and 26 to 28 DAI. Year of the experiment, the blocking factor, was treated as a random effect, whereas temperature, cultivar, and RH duration, the whole-, sub, and sub-sub-plot factors, respectively, were treated as fixed effects in the analyses. Prior to fitting the models, the dependent variables, blast incidence and severity, were arcsine-square roottransformed to stabilize variance. The model fitted to the data can be written as:

$$
\begin{aligned}
y_{i j k l} & =\theta+\alpha_{i}+\beta_{j}+\tau_{k}+(\alpha \beta)_{i j}+(\alpha \tau)_{i k}+(\beta \tau)_{j k} \\
& +(\alpha \beta \tau)_{i j k}+b_{l}+d_{i l}+w_{i j l}+e_{i j k l}
\end{aligned}
$$

where $y_{i j k l}$ is the response (dependent variable; $\operatorname{arcINC}$, arcSEV) for the $i$-th temperature (TEMP), $j$-th cultivar (CULT), and $k$-th high RH duration (RH) within in the $l$-th block (BLK), $\theta$ is the constant (intercept), $\alpha_{i}$ is the effect of the $i$-th TEMP, $\beta_{j}$ is the effect of the $j$-th CULT, $\tau_{k}$ is the effect of the $k$-th RH, $(\alpha \beta)_{i j}$ is the effect of the $i$-th TEMP $\times j$-th CULT interaction, $(\alpha \tau)_{i k}$ is the effect of the $i$-th TEMP $\times k$-th RH interaction, $(\beta \tau)_{j k}$ is the effect of the $j$-th CULT $\times k$-th RH interaction, $(\alpha \beta \tau)_{i j k}$ is the effect of the $i$-th TEMP $\times j$-th CULT $\times k$-th RH interaction, $b_{l}$ is the effect of the $l$-th BLK, $d_{i l}$ is the effect of the $i$ th TEMP $\times l$-th BLK interaction (whole-plot error), $w_{i j l}$ is the effect of $i$-th TRT $\times j$-th CULT $\times l$-th BLK interaction (subplot error), and $e_{i j k l}$ is the residual.

Mean blast incidence and severity on the arcsine-square roottransformed scale (arcINC and acrSEV) were compared among treatments and treatment combinations using lsmeans and lsmestimate statements in PROC GLIMMIX, with the $c l$ option specified to obtain estimates of the $95 \%$ confidence intervals around mean differences. For responses with statistically significant interaction effects, the slicediff option was used as part of lsmeans statements to perform simple-effect hypothesis tests of significance of each factor at each level of the other factors or combination of factors.

Linear and nonlinear regression analyses. Based on results from the LMM analyses (Table 1) and graphs of the raw data (Figs. 1 and 2), LMM regression analyses were performed on the data from the spray-inoculated experiment to estimate the rate of change in transformed spike blast incidence and severity per hour increase in high RH duration. The RH effect was generally not statistically significant in the point-inoculation experiment (see Results and Table 1). Separate models were fitted to transformed mean incidence and severity at 5 to 7 DAI, averaged across experiments, cultivars, and temperature, whereas separate models were fitted to the means at 20,25 , and $30^{\circ} \mathrm{C}$ at 12 to 14 and 19 to $21 \mathrm{DAI}$, averaged across experiments and cultivars. In all cases, the GLIMMIX procedure was used for model fitting, with parameter estimated and compared through estimate statements.

Results from the primary analyses in Table 1 also served as the basis for determining whether to quantify the effects of all temperature $\times \mathrm{RH}$ treatment combinations on the temporal progress of wheat blast. For the spray-inoculated experiments in which there was evidence of statistically significant temperature $\times \mathrm{RH}$ interaction effects, separate monomolecular, exponential, logistic, and Gompertz models (Madden et al. 2007) were fitted to the means for each combination, averaged across experiments and cultivars, whereas for the point-inoculated experiments in which the interactions were generally not statistically significant, separate models were fitted to the means for the 20,25 , and $30^{\circ} \mathrm{C}$ treatments, averaged across experiments, cultivars, and RH. In all cases, the NLIN procedure of SAS was used, and model performance was evaluated based on mean square error and coefficient of determination $\left(\mathrm{R}^{2}\right)$ from linear regression analysis of relationships between observed and predicted responses.

\section{Results}

Effects of temperature and relative humidity on mean wheat blast incidence and severity. Wheat spike blast developed equally well on both cultivars under all the tested conditions in both sprayand point-inoculated experiments. The first set of bleached, discolored spikelets were observed as early as 3 DAI, but both disease incidence and severity (together referred to here as intensity) remained extremely low across all treatments during the first week after inoculation (Fig. 1). For instance, only 22 of the 1,066 (2\%) spikes rated between 5 and 7 DAI in the spray-inoculated experiment were symptomatic. Averaged across spikes, treatment factors, and experiments, mean blast incidence and severity at 5 to 7 DAI were 1.4 and $0.45 \%$, respectively (Fig. 1A and C). The corresponding means were 1.4 and $5.9 \%$ in the point inoculated experiment (Fig. $1 \mathrm{~B}$ and D). These estimates increased substantially with time, reaching overall mean severity of $20 \%$ in the spray-inoculated experiment and $34 \%$ in the point-inoculated experiment at 19 to 21 DAI. Variability also increased as the disease progressed, with means ranging from 0 to $100 \%$ for both incidence and severity at 12 to 14 DAI. For instance, the interquartile ranges (IQR) for incidence in the spray inoculated experiment was 28.6, 55.6, and $66.7 \%$, at 12 to 14,19 to 21 , and 26 to 28 DAI, respectively (Fig. 1C). IQRs for incidence at similar time points in the point-inoculated experiment were $100 \%$.

Spray inoculation. Since results from LMM analyses showed that the main effect of cultivar and interactions involving cultivar were not statistically significant in most cases $(P>0.05$; Table 1$)$, attention was placed on the main and interaction effects of temperature and $\mathrm{RH}$ duration, averaged across cultivars. When spikes were spray-inoculated, mean differences between pairs of temperature treatments varied with $\mathrm{RH}$ duration and vice versa (statistically significant interactions, Table 1 ) at 12 to 14,19 to 21 , and 26 to 28 DAI, but not at the early assessment time (5 to 7 DAI) when disease intensity was very low. Early in the epidemic, temperature had a significant effect on arcsine square root-transformed incidence (arcINC) but not transformed severity (arcSEV), whereas RH significantly affected both responses. Averaged across temperatures, spikes exposed to $48 \mathrm{~h}$ of high RH immediately after inoculation had significantly higher mean arcINC and arcSEV at 5 to 7 DAI than those exposed to $0,3,6,12$, or $24 \mathrm{~h}$ of high RH (Fig. $2 \mathrm{~A}$ and B). Subsequent disease development was influenced by the interaction between temperature and RH duration. At 12 to 14 and 19 to 21 DAI, the effect of 
Table 1. Probability values (significance levels) from linear mixed model analyses of the effects of temperature, cultivar, relative humidity, and their interaction on arcsine-square root-transformed wheat spike blast incidence and severity at different times following inoculation with a spore suspension of an isolate (PL2-1) of the Lolium pathotype of Magnaporthe oryzae $(\mathrm{MoL})$

\begin{tabular}{|c|c|c|c|c|c|c|c|c|c|}
\hline \multirow[b]{2}{*}{ Experiment $^{\mathbf{a}}$} & \multirow[b]{2}{*}{ Factors $^{b}$} & \multicolumn{4}{|c|}{ Incidence $^{c}$} & \multicolumn{4}{|c|}{ Severity $^{c}$} \\
\hline & & 5 to 7 DAI & 12 to 14 DAI & 19 to 21 DAI & 26 to 28 DAI & 5 to 7 DAI & 12 to 14 DAI & 19 to $21 \mathrm{DAI}$ & 26 to 28 DAI \\
\hline \multirow[t]{7}{*}{ SPRAY } & TEMP & 0.041 & 0.003 & 0.019 & 0.002 & 0.106 & 0.003 & 0.001 & 0.009 \\
\hline & CULT & 0.754 & 0.286 & 0.049 & 0.492 & 0.605 & 0.715 & 0.009 & 0.743 \\
\hline & TEMP $\times$ CULT & 0.951 & 0.578 & 0.499 & 0.682 & 0.802 & 0.542 & 0.016 & 0.392 \\
\hline & RH & 0.017 & $<0.001$ & $<0.001$ & $<0.001$ & 0.012 & $<0.001$ & $<0.001$ & $<0.001$ \\
\hline & $\mathrm{TEMP} \times \mathrm{RH}$ & 0.351 & $<0.001$ & $<0.001$ & 0.001 & 0.250 & $<0.001$ & $<0.001$ & $<0.001$ \\
\hline & $\mathrm{CULT} \times \mathrm{RH}$ & 0.923 & 0.590 & 0.508 & 0.455 & 0.971 & 0.383 & 0.929 & 0.199 \\
\hline & $\mathrm{TEMP} \times \mathrm{CULT} \times \mathrm{RH}$ & 1.000 & 0.800 & 0.742 & 0.217 & 1.000 & 0.982 & 0.382 & 0.053 \\
\hline \multirow[t]{7}{*}{ POINT } & TEMP & $<0.001$ & 0.002 & 0.001 & $<0.001$ & 0.079 & 0.001 & 0.001 & 0.024 \\
\hline & CULT & 0.687 & 0.576 & 0.501 & 0.010 & 0.683 & 0.276 & 0.296 & 0.157 \\
\hline & TEMP $\times$ CULT & 0.958 & 0.523 & 0.981 & 0.142 & 0.867 & 0.495 & 0.294 & 0.501 \\
\hline & RH & 0.241 & 0.001 & 0.183 & 0.186 & 0.389 & 0.004 & 0.064 & 0.086 \\
\hline & $\mathrm{TEMP} \times \mathrm{RH}$ & 0.651 & 0.226 & 0.102 & 0.103 & 0.700 & 0.314 & 0.327 & 0.018 \\
\hline & $\mathrm{CULT} \times \mathrm{RH}$ & 0.699 & 0.648 & 0.691 & 0.002 & 0.655 & 0.301 & 0.894 & 0.005 \\
\hline & $\mathrm{TEMP} \times \mathrm{CULT} \times \mathrm{RH}$ & 0.983 & 0.005 & 0.981 & 0.101 & 0.854 & 0.003 & 0.694 & 0.094 \\
\hline
\end{tabular}

a Two methods of inoculation were used, each treated as a separate experiment. As the name suggests, in the SPRAY inoculated experiment, spikes were sprayed with a spore suspension of MoL. In the POINT inoculated experiment, a drop of the spore suspension was deposited directly inside a floret in the central portion of the spike.

b The treatment factors evaluated were temperature (TEMP), hours of high (>95\%) relative humidity immediately after inoculation (RH), and cultivar (CULT).

c Wheat spike blast incidence (mean proportion of diseased spikes in a sample) and severity (mean proportion of bleached, discolored spikelets per spike) at 5 to 7 ,

12 to 14,19 to 21 , and 26 to 28 days after inoculation (DAI).

Spray

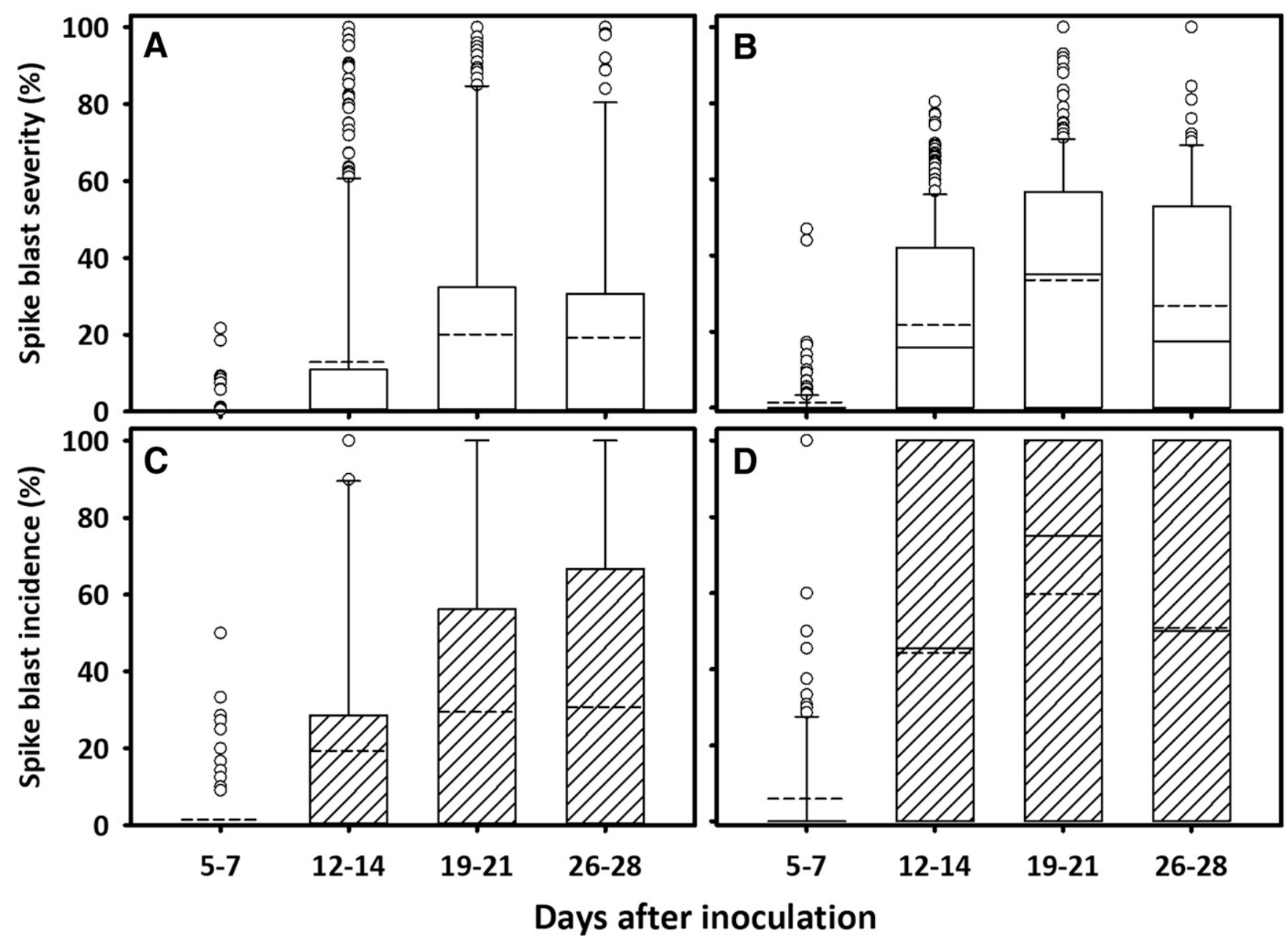

Fig. 1. Boxplots showing the distribution of mean wheat spike blast severity (A and $\mathbf{B})$ and incidence ( $\mathbf{C}$ and $\mathbf{D})$ at 5 to 7,12 to 14,19 to 21 , and 26 to 28 days after spray (A and $\mathbf{C}$ ) or point (B and $\mathbf{D}$ ) inoculation with a spore suspension of an isolate (PL2-1) of the Lolium pathotype of Magnaporthe oryzae. Broken and solid lines within each box represent means and medians, respectively, while the top and bottom lines of the box represent the 75th and 25th percentiles of the data, respectively. Vertical bars extending beyond the boxes represent the fifth and 95th percentiles, while circles represent outliers. 
temperature was only significant on spikes initially exposed to 12 , 24 , and $48 \mathrm{~h}$ of high $\mathrm{RH}$, and the effect of $\mathrm{RH}$ duration was significant at 25 and $30^{\circ} \mathrm{C}$, but not at $20^{\circ} \mathrm{C}$. In all cases, means increased as $\mathrm{RH}$ duration increased and were higher at 25 and $30^{\circ} \mathrm{C}$ than at $20^{\circ} \mathrm{C}$ on spikes initially exposed for 24 or $48 \mathrm{~h}$ of $\mathrm{RH}>95 \%$ (Fig. $2 \mathrm{C}$ to F).

There were significant, positive linear relationships between $\mathrm{RH}$ duration and arcINC and arcSEV at 5 to 7,12 to 14 , and 19 to 21 DAI (Fig. 3). At 5 to 7 DAI, rates of increase in transformed severity per hour increase in $\mathrm{RH}>95 \%$ was comparable between incidence (0.011 units/h) and severity (0.012 units/h) (Fig. 3A). However, even at the highest tested $\mathrm{RH}$ duration, neither estimated mean incidence nor severity exceeded $0.30 \%$ (Fig. 3B). Later in the epidemic, at 12 to 14 and 19 to $21 \mathrm{DAI}$, the rate of increase in transformed blast intensity per hour increase in $\mathrm{RH}$ was influenced by temperature. Slopes were not significantly different from zero at $20^{\circ} \mathrm{C}$ (not shown in Fig. 3), but at 12 to 14 and 19 to $21 \mathrm{DAI}$, slopes were positive and

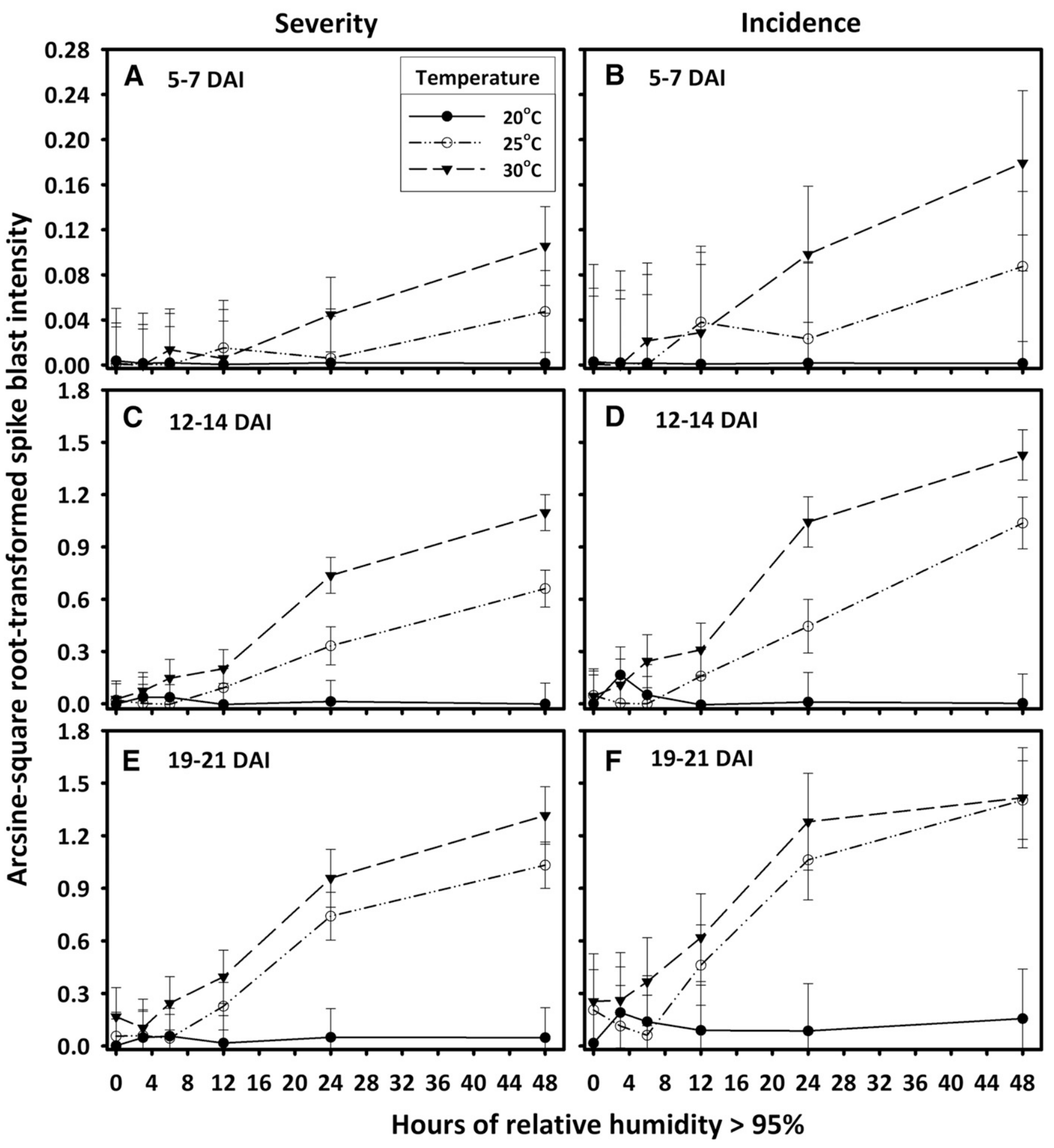

Fig. 2. Effects of temperature and the duration of high $(>95 \%)$ relative humidity immediately after spray inoculation on mean arcsine-square root-transformed spike blast severity (A, $\mathbf{C}$, and $\mathbf{E})$ and incidence $(\mathbf{B}, \mathbf{D}$, and $\mathbf{F})$ at 5 to $7(\mathbf{A}$ and $\mathbf{B}), 12$ to $14(\mathbf{C}$ and $\mathbf{D})$, and 19 to 21 ( $E$ and $\mathbf{F})$ days after inoculation with a spore suspension of an isolate (PL2-1) of the Lolium pathotype of Magnaporthe oryzae. Points represent least squares means across wheat spikes, experimental units, cultivars, and replicates. Error bars are $95 \%$ confidence intervals around the means. For both responses, the scale on the $y$-axis was allowed to vary to facilitate visualization and comparison of trends among temperature treatments and assessment times. 
significantly different from zero at 25 and $30^{\circ} \mathrm{C}$. The rates of increase in arcINC and arcSEV per hour increase in high $\mathrm{RH}$ were significantly greater $(P<0.001)$ at $30^{\circ} \mathrm{C}(0.024 / \mathrm{h})$ than at $25^{\circ} \mathrm{C}(0.015$ units/h) at 12 to $14 \mathrm{DAI}$, but not at 19 to $21 \mathrm{DAI}$ (Fig. 3C and E). At 12 to $14 \mathrm{DAI}$, the regression line was significantly higher at $30^{\circ} \mathrm{C}$ than at $25^{\circ} \mathrm{C}$ at 12,24 , and $48 \mathrm{~h}$ of high $\mathrm{RH}$ for arcSEV (Fig. 3C), and at $6,12,24$, and $48 \mathrm{~h}$ of high RH for arcINC (Fig. 3E). However, at 19 to $21 \mathrm{DAI}$, the difference in heights between the 25 and $30^{\circ} \mathrm{C}$ regression lines was not statistically significant for arcINC, and was only significant for arcSEV at 24 and $48 \mathrm{~h}$ of high RH. A greater number of hours of spike incubation at $\mathrm{RH}>95 \%$ was required at $25^{\circ} \mathrm{C}$ than at $30^{\circ} \mathrm{C}$ for blast to reach a certain intensity at a given time after inoculation (reference lines in Fig. 3D and F). For instance, at 12 to $14 \mathrm{DAI}$, an estimated mean severity of $25 \%$ was reached with $14.8 \mathrm{~h}$ of high $\mathrm{RH}$ at $30^{\circ} \mathrm{C}$ compared with $22.6 \mathrm{~h}$ at $25^{\circ} \mathrm{C}$ (Fig. 3D).

Point inoculation. When spores were deposited directly into the florets of the spikes, the effects of cultivar and interactions involving cultivars were again not statistically significant in the majority of cases (Table 1). The effect of temperature on arcINC and arcSEV at different times after inoculation was highly significant $(P<$ 0.05 ) in most cases, whereas the effects of high RH duration and interaction between temperature and high RH duration were generally not statistically significant $(P>0.05$; Table 1$)$. Contrary to what was observed in the spray-inoculated experiment, mean differences between pairs of temperature treatments generally were not influenced by RH duration (nonsignificant interactions in Table 1). The only exception was at 12 to $14 \mathrm{DAI}$ where the effects of RH duration and the

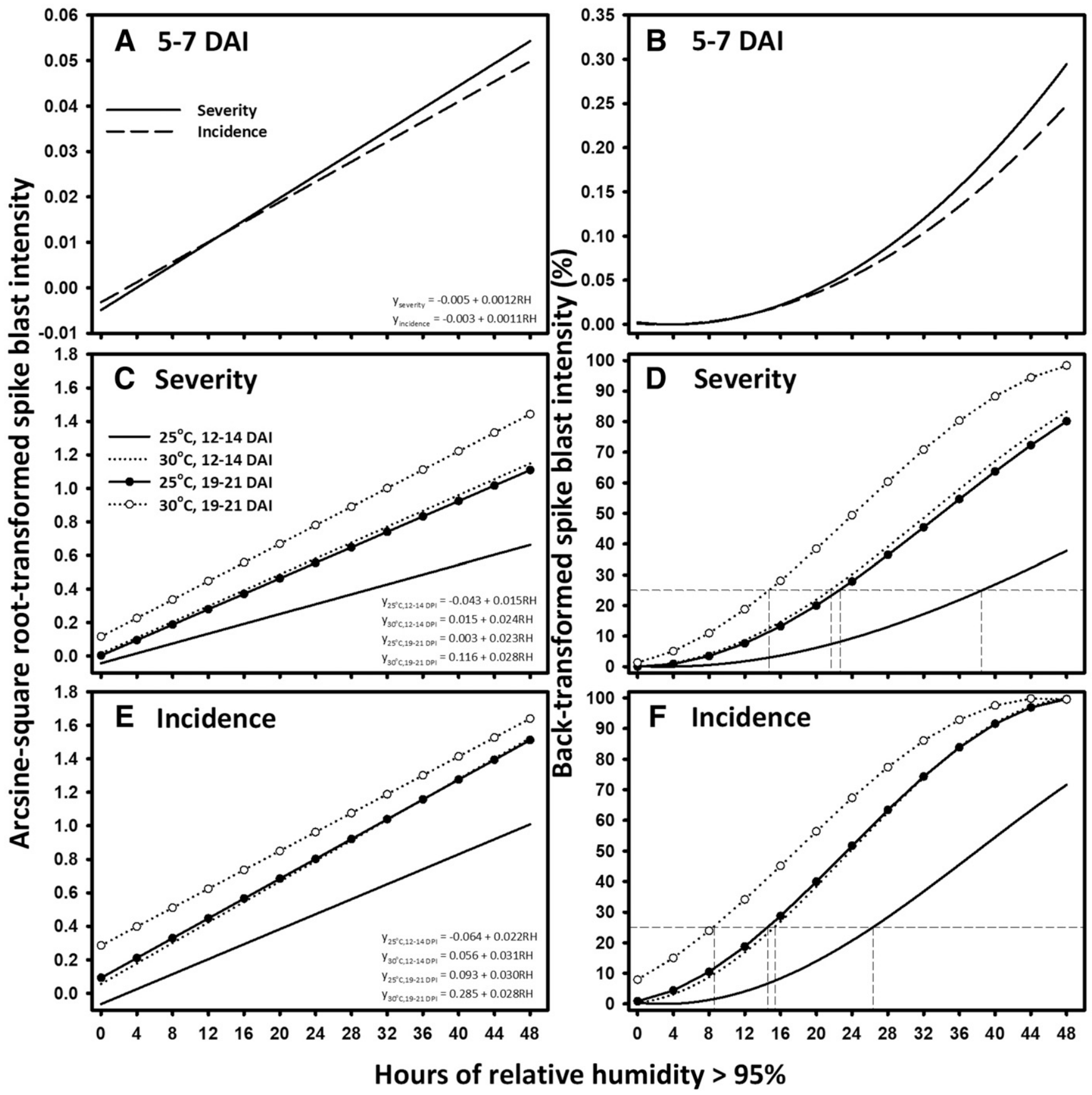

Fig. 3. Relationships between hours of exposure to high ( $>95 \%)$ relative humidity $(\mathrm{RH})$ immediately after spray inoculation with a spore suspension of an isolate (PL2-1) of the Lolium pathotype of Magnaporthe oryzae and arcsine-square root-transformed (A, C, and E) and back-transformed (B, D, and F) mean wheat spike blast severity and incidence at 5 to 7 (A and B) and 12 to 14 and 19 to 21 (C to F) days after inoculation. Inserts show model equations with intercept and slope parameters that were estimated through linear mixed model regression analyses with hours of high $\mathrm{RH}$ as a continuous covariate. A different scale was used on the $y$-axis in $\mathrm{A}$ and $\mathrm{B}$ to facilitate visualization of the trends at the low disease levels. 
three-way interaction were statistically significant, but even in this case, the temperature effect was highly significant at all tested levels of RH duration (meaning that the interaction was simply quantitative and not cross-over), contrary to what was observed when spikes were spray-inoculated. Transformed mean responses were higher at 30 and $25^{\circ} \mathrm{C}$ than at $20^{\circ} \mathrm{C}$, with all pairwise differences being highly significant at 12 to 14 and 19 to $21 \mathrm{DAI}$, for both incidence and severity (Fig. 4C to F). At 5 to $7 \mathrm{DAI}$, the temperature effect was highly significant for arcINC $(P<0.001$, Table 1$)$, but only marginally significant $(P=0.079)$ for arcSEV. Mean arcINC was significantly greater at $30^{\circ} \mathrm{C}$ than at 25 or $20^{\circ} \mathrm{C}$, but comparable between the latter two temperature treatments (Fig. $4 \mathrm{~A}$ and $\mathrm{B}$ ).

Trends in terms of monotonic relationships between spike blast intensity (incidence and severity) and hours of exposure to $\mathrm{RH}>95 \%$ immediately after inoculation were less clearly defined for pointinoculated spikes (Fig. 4) than those observed for spray-inoculated spikes (Fig. 2 and 3). Although means (transformed and observed) were numerically higher for the 24 and $48 \mathrm{~h}$ of high $\mathrm{RH}$ treatments at 5 to $7 \mathrm{DAI}$, trends were fairly flat across high $\mathrm{RH}$ durations later in the epidemic (Fig. 4). At 12 to 14 DAI, the timepoint at which

\section{Severity}

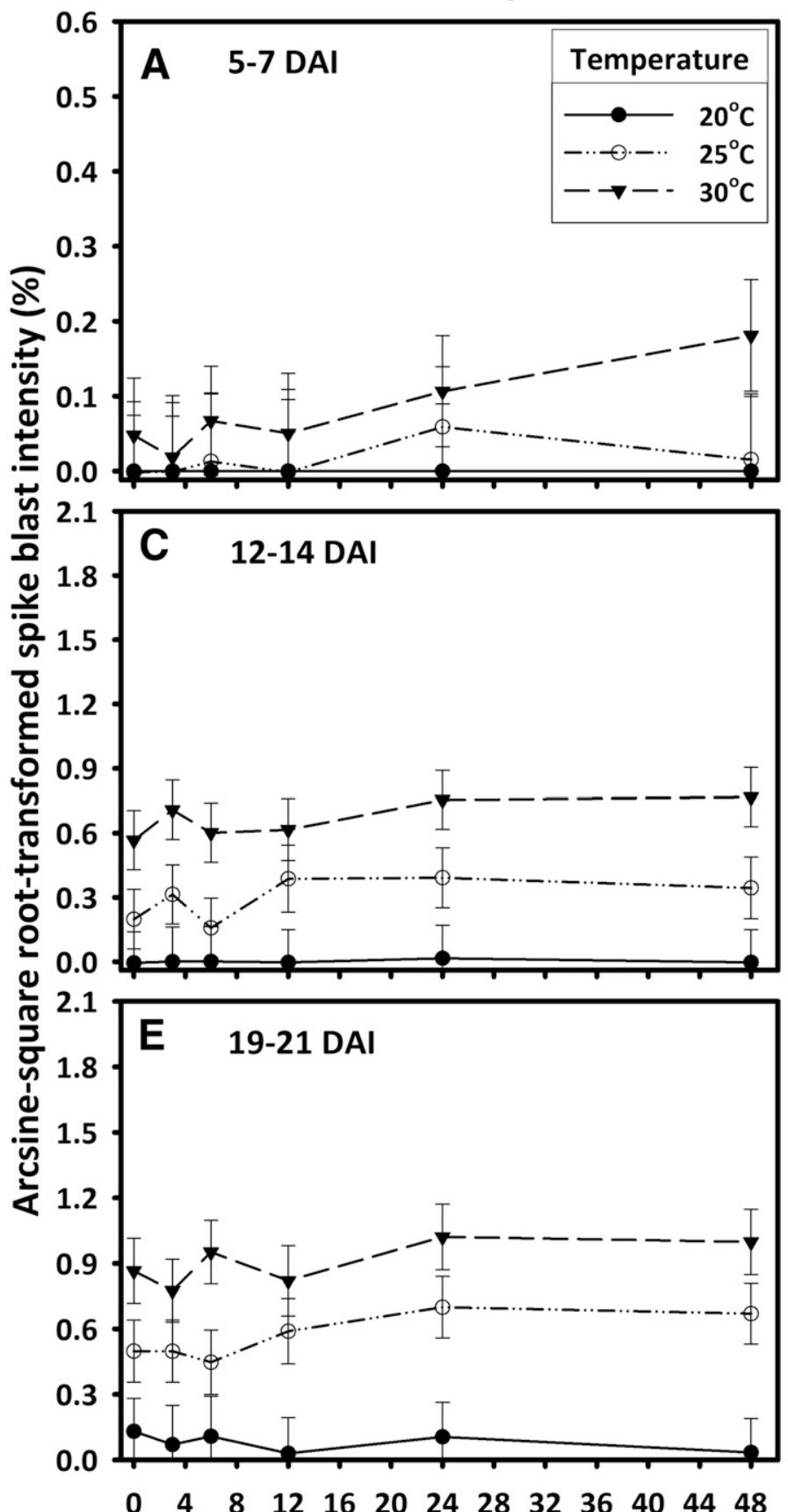

\section{Incidence}
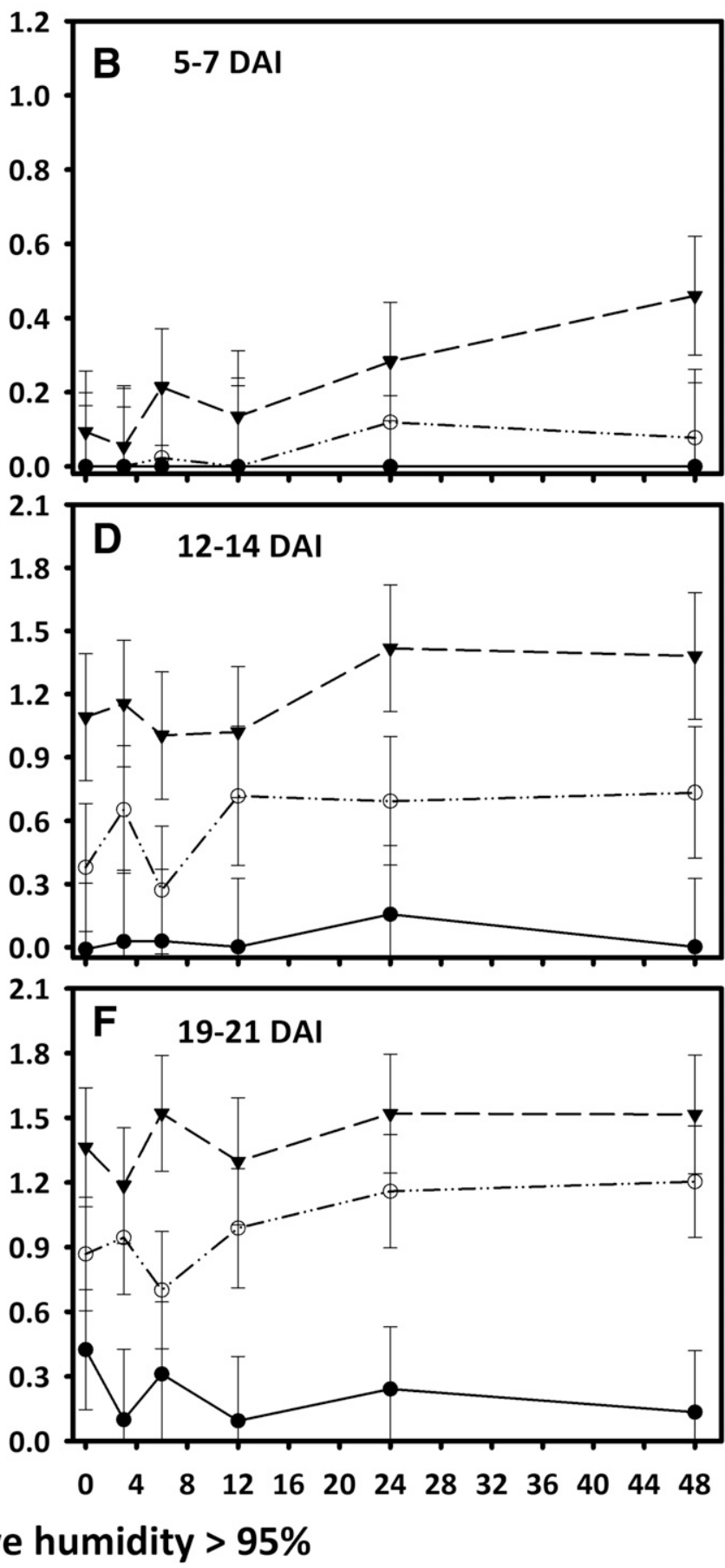

Fig. 4. Effects of temperature and the duration of high $(>95 \%)$ relative humidity immediately after point inoculation on mean arcsine-square root-transformed spike blast severity (A, $\mathbf{C}$, and $\mathbf{E}$ ) and incidence (B, D, and F) at 5 to $7(\mathbf{A}$ and $\mathbf{B}), 12$ to $14(\mathbf{C}$ and $\mathbf{D})$, and 19 to 21 ( $E$ and $F)$ days after inoculation with a spore suspension of an isolate (PL2-1) of the Lolium pathotype of Magnaporthe oryzae. Points represent least squares means across wheat spikes, experimental units, cultivars, and replicates. Error bars are $95 \%$ confidence intervals around the means. For both responses, the scale on the $y$-axis was allowed to vary to facilitate visualization and comparison of trends among temperature treatments and assessment times. 
the effect of high RH duration was highly significant (Table 1), there were significant positive relationships between the number of hours of incubation at high $\mathrm{RH}$ and arcINC and arcSEV, with a common slope across temperature treatments for both the RH-arcINC and the RH-arcSEV relationships. The rate of change in arcSEV per hour increase in high RH duration was $0.0025(\mathrm{SE}=0.0008)$ units $/ \mathrm{h}$, whereas arcINC increased at a rate of $0.0055(\mathrm{SE}=0.0015) \mathrm{units} / \mathrm{h}$ increase in high $\mathrm{RH}$ duration. These rates were considerably lower than those observed for corresponding relationships in the sprayinoculated experiment (Fig. 1C and E). Intercepts for the RH-acrSEV relationship were $-0.038(\mathrm{SE}=0.048), 0.259(\mathrm{SE}=0.045)$, and $0.638(\mathrm{SE}=0.045)$ for the $20^{\circ} \mathrm{C}, 25^{\circ} \mathrm{C}$, and $30^{\circ} \mathrm{C}$ temperature treatments, respectively. For the RH-arcINC relationship, the corresponding intercepts were $-0.054(\mathrm{SE}=0.108), 0.484(\mathrm{SE}=0.103)$, and 1.108 $(\mathrm{SE}=0.103)$. For both relationships, the regression lines were significantly higher $(P<0.05)$ at 30 and $25^{\circ} \mathrm{C}$ than at $20^{\circ} \mathrm{C}$, and higher at $30^{\circ} \mathrm{C}$ than at $25^{\circ} \mathrm{C}$.

Temperature and relative humidity effects on the temporal dynamics of wheat blast. The magnitude and significance of the main and interaction effects of temperature and high $\mathrm{RH}$ duration varied with DAI (Figs. 2 to 4), providing initial evidence of differential effects of treatment conditions on disease progress. In general, overall mean incidence and severity increased over time under all tested treatment conditions, but based on initial plots of the raw data (not shown), the temporal trend was considerably less well defined at the lowest tested temperature $\left(20^{\circ} \mathrm{C}\right)$ and shorter durations of high $\mathrm{RH}(0$ to $6 \mathrm{~h})$ when compared with the higher temperatures and longer RH durations. Therefore, only disease progress results for the latter set of conditions are emphasized and compared.

Based on the MSE and $\mathrm{R}^{2}$ values in Table 2, the Gompertz model was selected as the most appropriate for describing the temporal dynamics of wheat blast symptom development in most cases. In both spray- and point-inoculated experiments and for both responses, MSE values were very small, and close to or greater than $90 \%$ of the variation in observed blast intensity was explained by predicted intensity for the Gompertz model $\left(\mathrm{R}^{2}\right.$ in Table 2$)$. The only exceptions were for the epidemics that developed at $20^{\circ} \mathrm{C}$ for which the logistic or exponential models provided the best fit. Since it is not appropriate to use rate parameters to directly compare epidemics described by different models (Madden et al. 2007), properties of the disease progress curves and time to specific levels of incidence and severity were also used to compare the temporal dynamics of blast among treatments.

Temporal change in spike blast intensity. When spikes were sprayinoculated, blast progress curves were similar for epidemics at 25 and $30^{\circ} \mathrm{C}$, but considerably different at $20^{\circ} \mathrm{C}$ (Fig. 5A and C). At the low temperature, estimated incidence and severity remained lower $(<15 \%)$ during the first three weeks after inoculation than at the higher temperatures. Despite the similarities among progress curves at 25 and $30^{\circ} \mathrm{C}$ (Gompertz model was most appropriate to describe them all), the rate parameters $\left(r_{\mathrm{G}}\right)$ varied with temperature and $\mathrm{RH}$ duration (Table 2). For instance, for severity, the rate at $30^{\circ} \mathrm{C}$ with $48 \mathrm{~h}$ of high RH $\left(r_{\mathrm{G} 330: 48}=0.28 /\right.$ day $)$ was significantly greater $(P$ $<0.05)$ than for other temperature-RH-duration conditions $\left(r_{\mathrm{G}_{-} 30: 24}\right.$ (0.17/day), $r_{\mathrm{G} \_25: 24}(0.13 /$ day $)$, and $r_{\mathrm{G} \_25: 48}(0.15 /$ day $\left.)\right)$. The latter three rate parameters were not significantly different from each other. Similar trends were observed for incidence, with $r_{\mathrm{G} \_30: 48}(0.61 /$ day $)$ being significantly greater than $r_{\mathrm{G} \_30: 24}(0.24 /$ day $), r_{\mathrm{G} \_25: 24}(0.17 /$ day), and $r_{\mathrm{G} 25: 48}(0.28 /$ day $)$. RH duration also affected the rate of increase in incidence at $25^{\circ} \mathrm{C} ; r_{\mathrm{G}_{-} 25: 48}$ was significantly greater than $r_{\mathrm{G} \_25: 24}$ (Fig. 5C).

Time to $6,15,25$, and $50 \%$ severity, abbreviated as $t_{6}, t_{15}, t_{25}$, and $t_{50}$, respectively, was estimated as described by Madden et al. (2007) based on the model parameters in Table 2 and used as another way of comparing epidemics. In particular, this allowed for comparisons among epidemics described by different growth models. Since the mean number of spikelets per spike was 17 (average cross 3,259 spikes rates in the three experiments), with a single bleached spikelet corresponding to approximately $6 \%$ severity, $t_{6}$ was considered as a measure of the incubation period, i.e., the estimated mean time to the appearance of one (likely the first) bleached spikelet per spike. This period was within a fairly narrow range (6 to 9 days) at 25 and $30^{\circ} \mathrm{C}$ with 24 or $48 \mathrm{~h}$ of high $\mathrm{RH}$, but it took 2.5 to 4 times longer ( 24 days) at $20^{\circ} \mathrm{C}$, with $48 \mathrm{~h}$ of high $\mathrm{RH}$. Correspondingly, $t_{15}, t_{25}$, and $t_{50}$ were shortest under $30^{\circ} \mathrm{C}$ and $48 \mathrm{~h}$ of high RH, but they increased steadily as RH duration and temperature decreased (Table 2). This can be visualized as a shift to the right of the progress curves in Figure 5A. The time taken for 6, 15,25 , and $20 \%$ of the spikes to become symptomatic (incidence) followed a similar pattern (Table 2, Fig. 5C).

Table 2. Parameters and corresponding statistics from the fit of nonlinear forms of growth models to data from controlled environment studies of temporal development of wheat spike blast under different temperature and initial high relative humidity $(\mathrm{RH})$ conditions

\begin{tabular}{|c|c|c|c|c|c|c|c|c|c|c|c|c|}
\hline \multirow[b]{2}{*}{ EXPa } & \multirow[b]{2}{*}{ Response $^{\mathbf{b}}$} & \multirow[b]{2}{*}{ Conditions $^{\mathrm{c}}$} & \multicolumn{6}{|c|}{ Parameters and statistics ${ }^{d}$} & \multicolumn{4}{|c|}{ Time to $y$ blast intensity } \\
\hline & & & $y_{0}$ & $\operatorname{SE}\left(y_{0}\right)$ & Rate & $\operatorname{SE}(r)$ & MSE & $\mathbf{R}^{2}$ & 6 & 15 & 25 & 50 \\
\hline \multirow[t]{10}{*}{ SPRAY } & Severity & $20^{\circ} \mathrm{C}, 48 \mathrm{~h} \mathrm{RH}>95 \%$ & $1.7 \mathrm{E}-03$ & 7.2E-04 & $r_{\mathrm{E}}=0.15$ & 0.011 & 0.005 & 0.91 & 24 & 30 & 33 & 38 \\
\hline & & $25^{\circ} \mathrm{C}, 24 \mathrm{~h} \mathrm{RH}>95 \%$ & $6.6 \mathrm{E}-05$ & $1.6 \mathrm{E}-04$ & $r_{\mathrm{G}}=0.13$ & 0.013 & 0.008 & 0.91 & 9 & 12 & 15 & 20 \\
\hline & & $25^{\circ} \mathrm{C}, 48 \mathrm{~h} \mathrm{RH}>95 \%$ & 4.5E-04 & $6.1 \mathrm{E}-04$ & $r_{\mathrm{G}}=0.15$ & 0.011 & 0.005 & 0.96 & 7 & 9 & 11 & 16 \\
\hline & & $30^{\circ} \mathrm{C}, 24 \mathrm{~h} \mathrm{RH}>95 \%$ & $2.9 \mathrm{E}-04$ & $6.8 \mathrm{E}-04$ & $r_{\mathrm{G}}=0.17$ & 0.021 & 0.010 & 0.91 & 6 & 9 & 10 & 14 \\
\hline & & $30^{\circ} \mathrm{C}, 48 \mathrm{~h} \mathrm{RH}>95 \%$ & $1.5 \mathrm{E}-06$ & $1.0 \mathrm{E}-05$ & $r_{\mathrm{G}}=0.28$ & 0.047 & 0.016 & 0.89 & 6 & 7 & 8 & 11 \\
\hline & Incidence & $20^{\circ} \mathrm{C}, 48 \mathrm{~h} \mathrm{RH}>95 \%$ & $2.1 \mathrm{E}-03$ & $1.9 \mathrm{E}-03$ & $r_{\mathrm{L}}=0.19$ & 0.028 & 0.018 & 0.85 & 18 & 23 & 26 & 32 \\
\hline & & $25^{\circ} \mathrm{C}, 24 \mathrm{~h} \mathrm{RH}>95 \%$ & $6.9 \mathrm{E}-06$ & $2.5 \mathrm{E}-05$ & $r_{\mathrm{G}}=0.17$ & 0.019 & 0.010 & 0.93 & 8 & 11 & 13 & 17 \\
\hline & & $25^{\circ} \mathrm{C}, 48 \mathrm{~h} \mathrm{RH}>95 \%$ & 7.6E-09 & $6.2 \mathrm{E}-08$ & $r_{\mathrm{G}}=0.28$ & 0.038 & 0.010 & 0.93 & 7 & 8 & 9 & 12 \\
\hline & & $30^{\circ} \mathrm{C}, 24 \mathrm{~h}$ RH $>95 \%$ & 9.3E-05 & 3.2E-04 & $r_{\mathrm{G}}=0.24$ & 0.034 & 0.014 & 0.91 & 5 & 7 & 8 & 11 \\
\hline & & $30^{\circ} \mathrm{C}, 48 \mathrm{~h}$ RH $>95 \%$ & $1.1 \mathrm{E}-47$ & $9.5 \mathrm{E}-46$ & $r_{\mathrm{G}}=0.61$ & 0.098 & 0.007 & 0.96 & 6 & 7 & 7 & 8 \\
\hline \multirow[t]{6}{*}{ POINT } & Severity & $20^{\circ} \mathrm{C}$ & $1.4 \mathrm{E}-03$ & 9.4E-04 & $r_{\mathrm{E}}=0.14$ & 0.016 & 0.003 & 0.83 & 27 & 33 & 37 & 42 \\
\hline & & $25^{\circ} \mathrm{C}$ & $4.7 \mathrm{E}-03$ & $3.5 \mathrm{E}-03$ & $r_{\mathrm{G}}=0.08$ & 0.007 & 0.004 & 0.91 & 8 & 13 & 17 & 26 \\
\hline & & $30^{\circ} \mathrm{C}$ & 7.1E-03 & $5.0 \mathrm{E}-03$ & $r_{\mathrm{G}}=0.12$ & 0.010 & 0.004 & 0.94 & 5 & 8 & 11 & 16 \\
\hline & Incidence & $20^{\circ} \mathrm{C}$ & $1.9 \mathrm{E}-02$ & $6.9 \mathrm{E}-03$ & $r_{\mathrm{E}}=0.09$ & 0.010 & 0.014 & 0.84 & 13 & 23 & 29 & 36 \\
\hline & & $25^{\circ} \mathrm{C}$ & $5.0 \mathrm{E}-04$ & $6.4 \mathrm{E}-04$ & $r_{\mathrm{G}}=0.15$ & 0.011 & 0.005 & 0.96 & 7 & 9 & 11 & 16 \\
\hline & & $30^{\circ} \mathrm{C}$ & $9.2 \mathrm{E}-06$ & $2.9 \mathrm{E}-05$ & $r_{\mathrm{G}}=0.31$ & 0.029 & 0.005 & 0.97 & 5 & 6 & 7 & 9 \\
\hline
\end{tabular}

a Two methods of inoculation were used, each treated as a separate experiment. As the name suggests, in the SPRAY inoculated experiment, spikes were sprayed with a spore suspension of an isolate (PL2-1) of the Lolium pathotype of Magnaporthe oryzae. In the POINT inoculated experiment, a drop of the spore suspension was deposited directly inside a floret in the central portion of the spike.

${ }^{\mathrm{b}}$ Wheat spike blast incidence (mean proportion of diseased spikes in a sample) and severity (mean proportion of bleached, discolored spikelets per spike).

${ }^{\mathrm{c}}$ Inoculated spikes were subjected to different temperature and relative humidity treatments; RH represents the number of hours of high ( $\left.>95 \%\right)$ relative humidity immediately after inoculation.

${ }^{\mathrm{d}}$ Estimated $y_{0}$ (initial disease intensity) and rate parameters for exponential $\left(r_{\mathrm{E}}\right)$, Gompertz $\left(r_{\mathrm{G}}\right)$, and logistic $\left(r_{\mathrm{L}}\right)$ growth models, and their standard errors (SE). $\mathrm{MSE}=$ mean square error and $\mathrm{R}^{2}=$ coefficient of determination for relationship between predicted and observed mean spike blast incidence or severity 
Temporal spread of infection within spikes. In the point-inoculated experiment, severity rate parameters provide a measure of the mean rate of spread of the pathogen or infection within the spike. In other words, these parameters are indicative, at least in part, of the rate of colonization of the spike. Based on $r_{\mathrm{G}}$, which was significantly greater at $30^{\circ} \mathrm{C}$ than at $25^{\circ} \mathrm{C}$, colonization was much faster at 30 than at $25^{\circ} \mathrm{C}$. The fact that disease severity remained lower throughout the epidemic at $20^{\circ} \mathrm{C}$ than at 25 or $30^{\circ} \mathrm{C}$ indicates that spread of the pathogen within the spike was slowest and/or the incubation period was longest at the lowest tested temperature. The time taken for the pathogen to spread and symptoms to become evident on three new spikelets from the point of inoculation/infection (estimated as the difference between $t_{6}$ and $t_{25}$ ) was 9 to 10 days at $20^{\circ} \mathrm{C}$ and $25^{\circ} \mathrm{C}$, compared with 6 days at $30^{\circ} \mathrm{C}$ (Table 2). However, even at the highest tested temperature, blast severity did not reach $75 \%$ at the time of the last assessment (Fig. 5B).

On the other hand, final spike disease incidence reached and exceeded $90 \%$ at all three temperatures (Fig. 5D). Rate parameters for incidence can be interpreted in terms of the time taken for additional disease-free spikes to show visual symptoms of blast on at least one spikelet. As was the case with colonization, spikes within a sample developed visual symptoms much faster at 30 and $25^{\circ} \mathrm{C}$ than at $20^{\circ} \mathrm{C}$. For instance, it took 27 days longer for $50 \%$ of the pointinoculated spike to become symptomatic at $20^{\circ} \mathrm{C}$ than at $30^{\circ} \mathrm{C}$ (Table 2). Close to $100 \%$ of the spikes were diseased by $21 \mathrm{DAI}$ at $30^{\circ} \mathrm{C}$, compared with $76 \%$ at $25^{\circ} \mathrm{C}$ and $18 \%$ at $20^{\circ} \mathrm{C}$; it took an additional 3 weeks for $100 \%$ of spikes inoculated at $20^{\circ} \mathrm{C}$ to develop typical blast symptoms (Fig. 5D).

\section{Discussion}

We demonstrated here as did other researchers (Farman et al. 2017; Tosa et al. 2004; Urashima et al. 1993) that MoL is capable of infecting and causing typical spike blast symptoms on wheat. However, the fact that winter wheat is harvested between late spring and early summer in the U.S., well before GLS typically develops (Uddin et al. 2003b), may in part explain why natural MoL infections are not more frequent (Farman et al. 2017). Farman et al. (2017) hypothesized that temporal separation among the emergence of wheat spikes (Feekes growth state 10.5), GLS development on perennial ryegrass, and peak $M$. oryzae spore production in Kentucky was influenced by weather conditions. They further postulated that climate change will likely lead to conditions becoming more favorable for M. oryzae spore production during wheat heading, increasing the likelihood of future MoL-incited wheat blast epidemics in the U.S. The plasticity of $M$. oryzae in its ability to adapt to new hosts and environmental conditions, and the close relationship between isolates of the pathogen from wheat and perennial ryegrass (Uddin et al. 2003b), further support the likelihood of MoL-incited wheat blast becoming established in the U.S.

Findings from previous cross-infection studies designed specifically to determine whether MoL was capable of infecting wheat did not provide information on the epidemiology of the disease nor
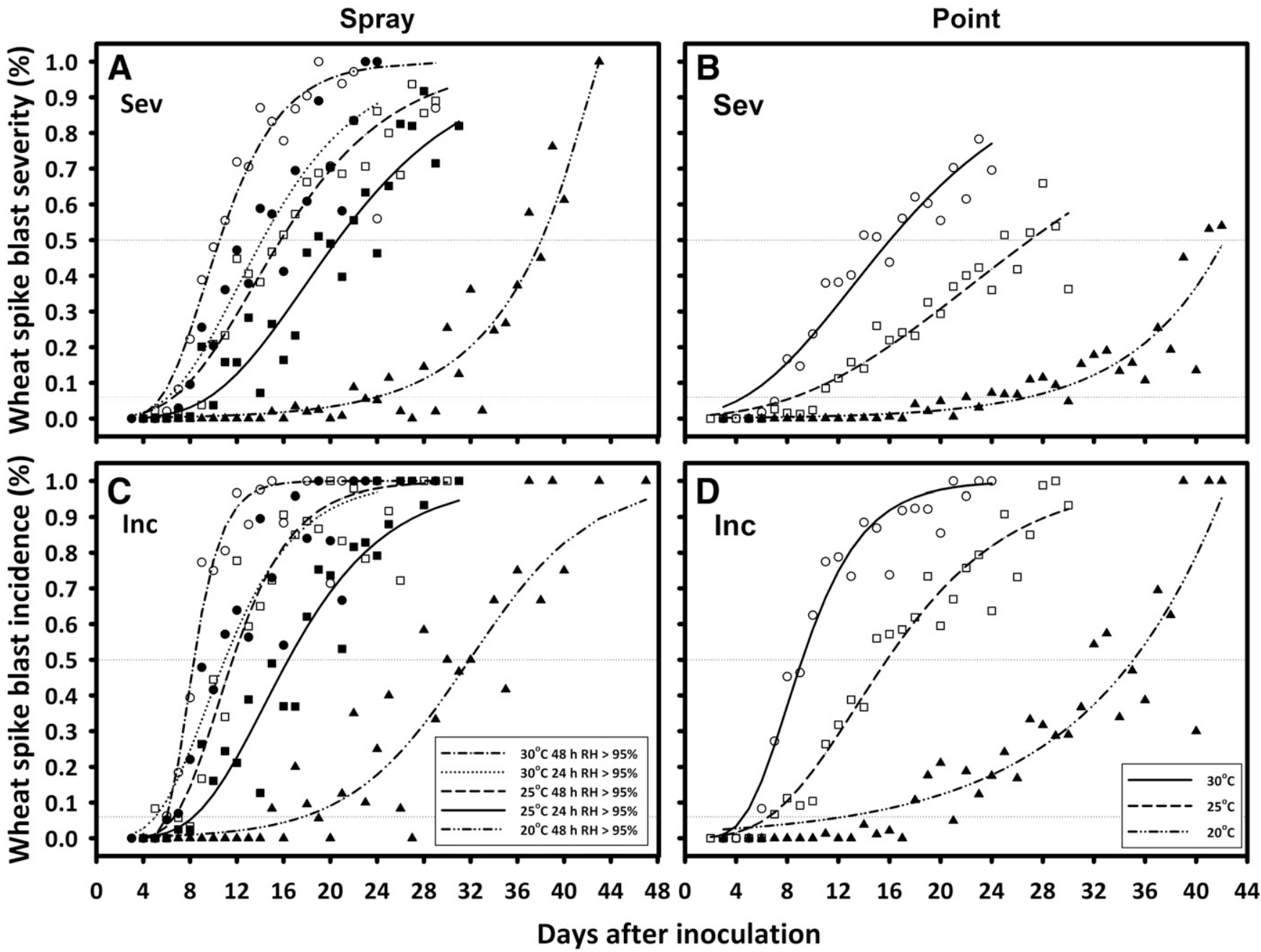

Fig. 5. Temporal change in mean wheat spike blast severity (A and $\mathbf{B})$ and incidence ( $\mathbf{C}$ and $\mathbf{D})$ under different temperature and high relative humidity (RH) durations (hours of $>95 \%$ RH immediately after inoculation) treatments or combinations following spray ( $\mathbf{A}$ and $\mathbf{C}$ ) or point (B and $\mathbf{D}$ ) inoculation with spore suspensions of an isolate (PL2-1) of the Lolium pathotype of Magnaporthe oryzae. Points represent means across wheat spikes, experimental units, cultivars, and replicates. Lines are predicted responses from nonlinear regression fit of growth models to the data for each temperature or temperature $\times$ hours of high (>95\%) RH treatment combination. Model parameters are in Table 2 . 
were they necessarily indicative of what was likely to occur in the field. For instance, some previous host-range studies demonstrating the ability of isolates of $M$. oryzae from rice or turfgrasses to infect wheat were based on inoculations of leaves on seedlings (Tosa et al. 2004; Urashima et al. 1993) instead of spikes, the plant part of greatest importance from the standpoint of grain yield and quality losses due to wheat blast. In addition, some host range studies were conducted using extremely high spore concentrations applied to plants under conditions that were highly conducive for infection (Tosa et al. 2004; Urashima et al. 1993). This makes it difficult to infer what is likely to occur in nature, as fixed, highly conducive, controlled conditions may force infections that likely would not occur in the field. Our study was the first to investigate the effects of different combinations of temperature and high relative humidity duration on spike blast development in the MoL-wheat pathosystem, generating insightful results on temporal disease dynamics.

We observed the highest mean levels of spike blast intensity and the highest temporal rates of increase in incidence and severity at 25 and $30^{\circ} \mathrm{C}$, with 24 and $48 \mathrm{~h}$ of high ( $\left.>95 \%\right)$ relative humidity immediately after inoculation (relative to the situation with $20^{\circ} \mathrm{C}$ and fewer than $12 \mathrm{~h}$ of high $\mathrm{RH}$ ). We then developed models describing relationships between hours of incubation at high RH and blast incidence and severity as well as the temporal dynamics of blast symptom development and spread within spikes as influenced by temperature and RH. While this is all novel for the MoL-wheat pathosystem, our results in terms of temperature and moisture effects were comparable to those reported from studies of $\mathrm{MoO}$ on rice, $\mathrm{MoL}$ on ryegrass, and MoT on spring wheats in South America. For instance, ideal conditions for rice blast to develop were reported to be temperatures between 25 and $28^{\circ} \mathrm{C}$, high relative humidity, and at least $4 \mathrm{~h}$ of leaf wetness (Greer and Webster 2001; Suzuki 1975). Similarly, based on a controlled-environment study similar to ours, Cardoso et al. (2008) reported that wheat blast was favored by temperatures of 25 and $30^{\circ} \mathrm{C}$, with at least $10 \mathrm{~h}$ of spike wetness; Uddin et al. (2003a) reported that GLS development on perennial ryegrass was favored by high temperatures $\left(28^{\circ} \mathrm{C}\right)$ with at least $24 \mathrm{~h}$ of leaf wetness; and the spread of wheat blast in South America was also found to be associated with a combination of $28^{\circ} \mathrm{C}$ and high RH (at least 90\%) (Alves and Fernandes 2006).

The two inoculation methods used in our experiments and knowledge of the epidemiology of other blast diseases (Suzuki 1975; Uddin et al. 2003b) allowed us to hypothesize about the role of temperature, and moisture in particular, on components of the infection cycle. We observed that duration of high RH was much more important for blast development when spores were spray-applied to the surface of spikes than deposited inside the florets. Based on work done with rice blast (Suzuki 1975) and GLS (Uddin et al. 2003b), the blast infection process involves spore germination and the formation of appressoria and penetration pegs, all of which require moisture. Assuming that these processes are the same for the MoL-wheat pathosystem, spores deposited directly into the floret of point inoculated spikes bypassed some of the surface-moisture constraints on infection, with spores likely having sufficient moisture inside the florets for infection to occur. On the other hand, spores applied to the surface of spikes and bagged for less than $12 \mathrm{~h}$ likely dried out, arresting germination, appressoria formation, and penetration. This is very consistent with what has been reported for $\mathrm{MoO}$, the rice blast pathotype of $M$. oryzae (Suzuki 1975). Optimum conditions for $\mathrm{MoO}$ spore germination and appressoria formation are temperatures between 25 and $28^{\circ} \mathrm{C}$ and 16 and $25^{\circ} \mathrm{C}$, respectively, and the presence of free water (Suzuki 1975). If the surface dries before appressoria are formed, the protoplasm of the spores coagulates and dies, and the extent to which appressoria formation is affected by drying is a function of the duration of wetness before the surface dries (Suzuki 1975).

The effects of moisture duration and temperature on infection would also explain the observed relationships between blast intensity and hours of incubation at $>95 \% \mathrm{RH}$. Both transformed incidence and severity for spray inoculation increased as high $\mathrm{RH}$ duration increased, but intercepts, and to a lesser extent, slopes for $\mathrm{RH}-\operatorname{arcINC}$ and RH-arcSEV relationships varied with temperature.
These relationships were better defined and more consistent at 25 and $30^{\circ} \mathrm{C}$ than at $20^{\circ} \mathrm{C}$ (where disease intensity was much lower). For our experiments in which applied spores were the only source of inoculum and moisture treatments were only imposed during the first 3 to $48 \mathrm{~h}$ after inoculation, an increase in incidence with increasing high $\mathrm{RH}$ duration would be equivalent to an increase in the number of spikes initially infected that showed visual symptoms. The same rationale can be used to explain relationships between severity and high RH duration. Spike blast severity as defined in our study is really a measure of incidence at the spikelet level. Therefore, at a fixed time after inoculation, the rate of increase in severity on spray-inoculated spikes per hour increase in high RH duration would have been largely a function of the rate of increase in the mean number of symptomatic spikelets that were initially infected per spike per hour increase in high RH. For reasons discussed above based on work done with MoO on rice (Suzuki 1975), the number of spores that remined viable, germinated, and successfully infected (spikes within a sample and spikelets on spike) likely increased as moisture duration increased, leading to higher incidence and severity. Higher $\mathrm{RH}$-arcSEV regression lines at 30 than at $25^{\circ} \mathrm{C}$, particularly at 24 and $48 \mathrm{~h}$ of high $\mathrm{RH}$, could also be explained by the fact that the number of spikelets initially infected and developed symptoms was likely greater at 30 than at $25^{\circ} \mathrm{C}$.

Following initial infection in both the spray- and point-inoculated experiments, blast intensity increased over time at all tested temperatures, particularly when spikes were exposed to 12 or more hours of $>95 \% \mathrm{RH}$ immediately after inoculation. However, the shape of the disease progress curves over days after inoculation varied among temperature $\times \mathrm{RH}$ combinations on spray-inoculated spikes and among temperature treatments on spikes that were pointinoculated. Gongora-Canul et al. (2020) and Rios et al. (2016) observed temporal increases in MoT-incited spike blast intensity under field conditions, with progress curves that varied with in-field inoculum and management practices, respectively. Progress curves are graphical depictions of epidemics that summarize interactions among hosts, pathogens, and the environment (Madden et al. 2007). Curves of the types (mostly S-shaped, sigmoid) observed in our experiments are often used to describe polycyclic diseases/epidemics, where diseased plants or tissues produce inoculum that are disseminated to new disease-free plants or plant parts where they infect, causing disease intensity to increase over time. However, because of the way our study was conducted and the fact that the growth stage of greatest susceptibility is close to anthesis (K. B. Mills, unpublished), spike blast intensity does not fit the classical definition of a polycyclic epidemic. Spores produced during the epidemics were not the drivers of the observed temporal increases in incidence and severity in the growth chambers, since sporulation occurred several days or weeks after symptom development, and consequently after the growth states of greatest host susceptibility (K. B. Mills, unpublished). Conditions in the growth chambers were not the most conducive to secondary infection as a result of spore dissemination.

As discussed by Berger et al. (1997) and demonstrated by Paul and Munkvold (2005), new infections and secondary cycles are not the only drivers of temporal disease progress. Lesion expansion is another component of epidemics that may be more important than new infections for temporal disease increase in some situations. This was certainly the case with wheat blast severity in our study. Given that spikes were inoculated once, and in the case of point-inoculation, in a single spikelet, temporal increases in severity were likely due to spread within the spike, a type of lesion expansion. The rate at which this occurred depended on temperature and high RH duration. These variables affected initial infection as discussed above and subsequent colonization, leading to differences in the severity progress curves over days among treatment combinations. Differences in the rate of lesion expansion would also be a plausible explanation for differences in disease progress between spray- and point-inoculated spikes. In the former case, several spikelets likely became infected initially, leading to spread from multiple points along the spike, compared with the latter where spread within the spike occurred from a single point. This suggests a higher $r_{G}$ for spray versus point 
inoculation, which we indeed found for temperatures above $20^{\circ} \mathrm{C}$. This resulted in higher mean severity at any given time after inoculation and higher final severity on spray-inoculated compared with point-inoculated spikes. For incidence, we hypothesize that temporal increases and differences in progress curves among treatments were due to differences in the time it took for inoculated spikes to develop visual symptoms (incubation period). Although spikes were inoculated at about the same growth stage, whether or not they developed visual symptoms and the time it took for that to occur depended on the imposed temperature-RH treatments. This reflects, in part, the distribution of incubation time (Madden et al. 2007) for this disease under these controlled environmental conditions.

The Gompertz growth model best described all the epidemics that developed at 25 and $30^{\circ} \mathrm{C}$ with high RH duration greater than $12 \mathrm{~h}$. This is consistent with results from a study of the temporal dynamics of wheat spike blast in an area of Bolivia where the disease is endemic (Gongora-Canul et al. 2020). As discussed extensively in classical plant disease epidemiology literature (Berger 1981; Campbell and Madden 1990; Madden et al. 2007; Waggoner 1986), this model often provides a better fit than the logistic or other growth models to epidemics with positively skewed progress curves, i.e., epidemics for which most of the area under the curve is to the right of the inflection point. This is often explained in terms of the absolute rate of progress as those epidemics for which the rates approach the point of infection quickly and then decline slowly; in other words, epidemics that develop very rapidly during the first few days or weeks. These trends can be gleaned from the 25 and $30^{\circ} \mathrm{C}$ disease progress curves, all of which have a relatively short lag phase. Such a rapid early increase in disease intensity at 25 and $30^{\circ} \mathrm{C}$ with more than $12 \mathrm{~h}$ of high $\mathrm{RH}$ duration can again be attributed to higher levels of infection, shorter incubation period, and faster spread within the spike (colonization) under warm, humid conditions compared with cool, dry conditions $\left(20^{\circ} \mathrm{C}\right.$ and $<12 \mathrm{~h}$ of high $\left.\mathrm{RH}\right)$. Under less conducive conditions for disease development, the exponential was the best-fit model. This is consistent with a statement made by Madden et al. (2007) about the exponential model being unrealistic, but a good approximation of more complex models at the start of an epidemic when disease intensity is generally very low.

From our experiments: 1) we showed that like other blast diseases, MoL-incited blast is favored by warm, wet conditions; 2) we developed models for relationships between blast intensity and hours of $>95 \% \mathrm{RH}$, generating results useful for understanding the environmental conditions driving infection; 3 ) based on results from pointand spray-inoculation, we formulated hypotheses about the possible role of incubation period and lesion expansion in spike blast epidemics; and 4) we modeled the temporal dynamics of wheat as influenced by temperature and high RH duration, with results suggesting that MoL-incited spike blast is a polycyclic-type disease at the scale of the spikelet, which under highly favorable conditions is best described by the Gompertz growth models. Similarities between our results and those from studies conducted in South America, where MoT is the causal agent of wheat blast, suggest that the epidemiology of MoL-incited wheat blast may be similar to that of MoT-incited blast. This means that our results could potentially be used to assess disease risk, regardless of which of two pathotypes is causing the infections. However, further research would be needed to formally evaluate the effects of other factors such as MoT and MoL isolates, cultivar resistance, and cyclic temperate and $\mathrm{RH}$ regimes on spike blast temporal development. While we anticipate that the absolute value of some of the estimates will likely change under different conditions, trends will likely remain the same, leading to similar conclusions. Our findings are valuable for ongoing efforts to better understand the biology and epidemiology of wheat blast in general, but more specifically, to assess the risk posed by MoL to U.S. wheat and develop strategies for disease control. For instance, inoculation protocols from our study could be useful for characterizing resistance to MoL, and parameters from our models could be used to develop risk assessment models for MoL-incited wheat blast in the U.S. similar to the climate suitability models developed by Cruz et al. (2016) for MoT.

\section{Literature Cited}

Alves, K. J., and Fernandes, J. M. 2006. Influência da temperatura e da umidade relativa do ar na esporulação de Magnaporthe grisea em trigo. Fitopatol. Bras. 31:579-584.

Andersen, K. F., Madden, L. V., and Paul, P. A. 2015. Fusarium head blight development and deoxynivalenol accumulation in wheat as influenced by post-anthesis moisture patterns. Phytopathology 105:210-219.

Berger, R. D. 1981. Comparison of the Gompertz and logistic equations to describe plant disease progress. Phytopathology 71:716-719.

Berger, R. D., Bergamin Filho, A., and Amorim, L. 1997. Lesion expansion as an epidemic component. Phytopathology 87:1005-1013.

Campbell, C. L., and Madden, L. V. 1990. Introduction to Plant Disease Epidemiology. John Wiley \& Sons, New York.

Cardoso, C. A. de A., Reis, E. M., and Moreira, E. N. 2008. Development of a warning system for wheat blast caused by Pyricularia grisea. Summa Phytopathol. 34:216-221.

Castroagudın, V. L., Moreira, S. I., Pereira, D. A. S., Moreira, S. S., Brunner, P. C., Maciel, J. L. N., Crous, P. W., McDonald, B. A., Alves, E., and Ceresini, P. C. 2016. Pyricularia graministritici, a new Pyricularia species causing wheat blast. Persoonia 37:199-216.

Ceresini, P. C., Castroagudiin, V. L., Rodrigues, F. A., Rios, J. A., Aucique-Pérez, C. E., Moreira, S. I., Alves, E., Croll, D., and Maciel, J. L. 2018. Wheat blast: past, present, and future. Annu. Rev. Phytopathol. 56:427-456.

Ceresini, P. C., Castroagudiin, V. L., Rodrigues, F. A., Rios, J. A., Aucique-Pérez, C. E., Moreira, S. I., Croll, D., Alves, E., Carvalho, G., Maciel, J. L., and McDonald, B. A. 2019. Wheat blast: from its origins in South America to its emergence as a global threat. Mol. Plant Pathol. 20:155-172.

Couch, B. C., Fudal, I., Lebrun, M., Tharreau, D., Valent, B., van Kim, P., Notteghem, J. L., and Kohn, L. M. 2005. Origins of host-specific populations of the blast pathogen Magnaporthe oryzae in crop domestication with subsequent expansion of pandemic clones on rice and weeds of rice. Genetics 170:613-630.

Cruz, C. D., Bockus, W. W., Stack, J. P., Tang, X., Valent, B., Pedley, K. F., and Peterson, G. L. 2012. Preliminary assessment of resistance among U.S. wheat cultivars to the Triticum pathotypes of Magnaporthe oryzae. Plant Dis. 96: 1501-1505.

Cruz, C. D., Magarey, R. D., Christie, D. N., Fowler, G. A., Fernandes, J. M., Bockus, W. W., Valent, B., and Stack, J. P. 2016. Climate suitability for Magnaporthe oryzae Triticum pathotype in the United States. Plant Dis. 100:1979-1987.

Cruz, C. D., and Valent, B. 2017. Wheat blast disease: danger on the move. Trop Plant Pathol. 42:210-222.

Farman, M., Peterson, G., Chen, L., Starnes, J., Valent, B., Bachi, P., Murdock, L. Hershman, D., Pedley, K., Fernandes, J. M., and Bavaresco, J. 2017. The lolium pathotype of Magnaporthe oryzae recovered from a single blasted wheat plant in the United States. Plant Dis. 101:684-692.

Gladieux, P., Condon, B., Ravel, S., Soanes, D., Maciel, J. L. N., Nhani, A., Chen, L., Terauchi, R., Lebrun, M.-H., Tharreau, D., Mitchell, T., Pedley, K. F., Valent, B., Talbot, N. J., Farman, M., and Fournier, E. 2018. Gene flow between divergent cereal- and grass-specific lineages of the rice blast fungus Magnaporthe oryzae. MBio 9:e01219-17.

Gongora-Canul, C., Salgado, J. D., Singh, D., Cruz, A. P., Cotrozzi, L., Couture, J., Rivadeneira, M. G., Cruppe, G., Valent, B., Todd, T., Poland, J., and Cruz, C. D. 2020. Temporal dynamics of wheat blast epidemics and disease measurements using multispectral imagery. Phytopathology 110:393-405.

Goulart, A. C. P., Sousa, P. G., and Urashima, A. S. 2007. Danos em trigo causados pela infecção de Pyricularia grisea. Summa Phytopathol. 33:358-363.

Greer, C. A., and Webster, R. K. 2001. Occurrence, distribution, epidemiology, cultivar reaction, and management of rice blast disease in California. Plant Dis. 85:1096-1102.

Harmon, P. F., and Latin, R. 2003. Gray leaf spot of perennial ryegrass. Plant Health Progress. doi.org/10.1094/PHP-2003-1223-01-DG

Inoue, Y., Vy, T. T., Yoshida, K., Asano, H., Mitsuoka, C., Asuke, S., Anh, V., Cumagun, C. J., Chuma, I., Terauchi, R., Kato, K., Mitchell, T., Valent, B., Farman, M., and Tosa, Y. 2017. Evolution of the wheat blast fungus through functional losses ni a host specificity determinant. Science 357:80-83.

Kohli, M. M., Mehta, Y. R., Guzman, E., Viedma, L., and Cubilla, L. E. 2011 Pyricularia blast - a threat to wheat cultivation. Czech J. Genet. Plant Breed. 47:S130-S134

Madden, L. V., Hughes, G., and van den Bosch, F. 2007. The Study of Plant Disease Epidemics. American Phytopathological Society, St. Paul, MN.

Milazzo, J., Pordel, A., Ravel, S., and Tharreau, D. 2019. First scientific report of Pyricularia oryzae causing gray leaf spot disease on perennial ryegrass (Lolium perenne) in France. Plant Dis. 103:1024.

Mills, K. B., Paul, P. A., Madden, L. V., and Peterson, G. L. 2015. Preliminary assessment of differential susceptibility of northern soft red winter wheat cultivars to Lolium and Triticum pathotypes of Magnaporthe oryzae. Phytopathology 105:S4.96.

Paul, P. A., El-Allaf, S. M., Lipps, P. E., and Madden, L. V. 2005. Relationships between incidence and severity of Fusarium head blight on winter wheat in Ohio. Phytopathology 95:1049-1060.

Paul, P. A., and Munkvold, G. P. 2005. Influence of temperature and relative humidity on sporulation of Cercospora zeae-maydis and expansion of gray leaf spot lesions on maize leaves. Plant Dis. 89:624-630. 
Rios, J. A., Rios, V. S., Paul, P. A., Souza, M. A., Araujo, L., and Rodrigues, F. A. 2016. Fungicide and cultivar effects on the development and temporal progress of wheat blast under field conditions. Crop Prot. 89:152-160.

Sadat, A., and Choi, J. 2017. Wheat blast: A new fungal inhabitant to Bangladesh threatening world wheat production. Plant Pathol. 33:103-108.

Saharan, M. S., Bhardwaj, S. C., Chatrath, R., Sharma, P., Choudhary, A. K., and Gupta, R. K. 2017. Wheat blast disease-an overview. J. Wheat Res. 8:1-5.

Stroup, W. W., Milliken, G. A., Claassen, E. A., and Wolfinger, R. D. 2018. SAS for Mixed Models: Introduction and Basic Applications. SAS Institute Inc., Cary, NC.

Suzuki, H. 1975. Meteorological factors in the epidemiology of rice blast. Annu. Rev. Phytopathol. 13:239-256.

Tosa, Y., Hirata, K., Tamba, H., Nakagawa, S., Chuma, I., Isobe, C., Osue, J., Urashima, A. S., Don, L. D., Kusaba, M., Nakayashiki, H., Tanaka, A., Tani, T., Mori, N., and Mayama, S. 2004. Genetic constitution and pathogenicity of Lolium isolates of Magnaporthe oryzae in comparison with host speciesspecific pathotypes of the blast fungus. Phytopathology 94:454-462.
Uddin, W., Serlemitsos, K., and Viji, G. 2003a. A temperature and leaf wetness duration-based model for prediction of gray leaf spot of perennial ryegrass turf. Phytopathology 93:336-343.

Uddin, W., Viji, G., and Vincelli, P. 2003b. Gray leaf spot (blast) of perennial ryegrass turf: an emerging problem for the turfgrass industry. Plant Dis. 87: 880-889.

Urashima, A. S., Igarashi, S., and Kato, H. 1993. Host range, mating type, and fertility of Pyricularia grisea from wheat in Brazil. Plant Dis. 77:1211-1216.

Valent, B., Farman, M., Tosa, Y., Begerow, D., Fournier, E., Gladieux, P., Islam, M. T., Kamoun, S., Kemler, M., Kohn, L. M., Lebrun, M.-H., Stajich, J. E., Talbot, N. J., Terauchi, R., Tharreau, R., and Zhang, N. 2019. Pyricularia graminis-tritici is not the correct species name for the wheat blast fungus: response to Ceresini et al. (MPP 20:2). Mol. Plant Pathol. 20:173-179.

Waggoner, P. E. 1986. Progress curves of foliar diseases: Their interpretation and use. Pages 3-37 in: Plant Disease Epidemiology. Vol. 1. Population Dynamics and Management. K. J. Leonard and W. E. Fry, eds. Macmillan Publishing Co., New York 